\title{
Lest they forget: exploring commemoration and remembrance through games and digital technologies
}

lain Donald

Donald I. (2019) Lest they forget: exploring commemoration and remembrance through games and digital technologies. In: Kerby M., Baguley M., McDonald J. (eds) The Palgrave Handbook of Artistic and Cultural Responses to War since 1914. Palgrave Macmillan, Cham .

Reproduced with permission of Palgrave Macmillan. This extract is taken from the author's original manuscript and has not been edited. The definitive, published, version of record is available from:

https://doi.org/10.1007/978-3-319-96986-2_24 


\title{
Lest They Forget: Exploring Commemoration and Remembrance through Games and \\ Digital Technologies.
}

\author{
Iain Donald
}

Abertay University

\begin{abstract}
The centennial of the First World War has encouraged a wide range of projects to commemorate the participants and communities affected by the conflict. This paper considers how games and interactivity can be used to enhance commemoration and remembrance with new audiences. Finally, the digital commemorations undertaken for the Battle of Loos, and as part of the wider 'Great War Dundee,' project will be discussed. Emphasis is placed on how game design techniques and technology were utilized to plan an empathy game and then further developed into the interactive documentary and visualization, Loos: The Fallen Fourth. This artefact was created to disseminate fresh historical research and foster wider public engagement about the impact of the war and to develop further research avenues. The narratives that developed reflect the diversity of an industrial city and consider where the war mirrored or changed the social, economic and cultural structures of Dundee. The chapter concludes with a consideration of how these narratives engaged with the community and helped shape the wider understanding of the facts and myths that develop over a century of remembrance. The digital components of this project can be accessed via greatwardundee.com and greatwardundee.itch.io.
\end{abstract}

\section{Keywords (15-20)}

Games, Interactive Documentary, History, Historical Games, First World War, Commemoration, Remembrance, Visualization, Community, Communal Memory, Collective Memory, Public Engagement, Dundee, $4^{\text {th }}$ Black Watch, Scotland, Great War Dundee, Loos, Loos: The Fallen Fourth (18) 


\section{Introduction}

The use of mass media whether novels, films, television or games in the teaching of history is often a double-edged sword. On the one hand they stimulate interest and engage hard to reach audiences and on the other they too often provide a single, simplified interpretation of complex issues. Understandably historians have often been wary of games as both a teaching tool or as a valid research medium. Yet games are arguably the mass media of the twenty-first century ${ }^{1}$, a platform where the relationship between the message and the medium is intertwined with opportunities for learning and playing with outcomes in a virtual world. ${ }^{2}$ Games are not only at the forefront of new forms of interaction and audience participation but are increasingly valid cultural artefacts and critiques of their time. ${ }^{3}$ Games should also be viewed as essential tools for historians to connect younger and digitally-native generations to the past because they are a valid tool for encouraging new solutions for dissemination. ${ }^{4}$ The best games and other forms of interactive content are not dissimilar to the finest museum experiences, allowing people to explore, interact with objects and providing complimentary research-based narratives. This chapter explores the use of games and digital content to present historical data and interpretation within the context of the Heritage Lottery Funded (HLF) project, Great War Dundee (GWD), and will place into context game and digital content design for public engagement.

\section{Background}

Although it hardly seems possible, for the majority of people the First World War is now an abstract concept. There are no living veterans and the complex story of the war is further hindered by limited mass media interest (in contrast to the Second World War and more recent conflicts) and a narrative that is shaped as much by myth as by fact. The effect of this is that the narrative, which when understood and appreciated in the context of the times, is even more tragic in respect 
to the lives lost. The original proposal for the GWD project aimed to co-ordinate a city-wide approach to the centenary commemoration of the First World War in Dundee, bringing the community together with the city's museums, archives, libraries, universities and societies through a program of activities that encouraged the broadest possible public participation and collective reminiscence. ${ }^{5}$ The program of activities was to include exhibitions, talks, drama performances, film screenings, publications, a website and the creation of a game. In doing so the project intended to raise awareness of the involvement in the war of the city and its people at home and abroad, particularly highlighting less well-known or forgotten stories and subjects. A key aspect to this project was to encourage young people in Dundee to understand better the impact of the war in their own city, via workshops and school resources, and, ensure a legacy for the project through the creation of the GWD website that will tell the personal stories of 'Dundonians' in wartime. The project aimed to encourage the digital preservation of privately owned material which might otherwise be lost. It was a natural step, given Dundee's expertise in game development, to include the creation of a game that would help engage with a wider audience, convey selected historical narratives and establish a digital legacy for the project. ${ }^{6}$ The bold proposal was ultimately successful in securing a HLF grant and commenced in early 2014.

The First World War tore the heart out of communities across all the countries involved in the conflict and Scotland was no different. For the City of Dundee, over 4000 men died, and the war scarred an entire generation of the city's youth. The number of those killed represents a devastating casualty rate of over $15 \%$ of Dundee men on active service - nearly double that of Glasgow, hitherto thought to be one of the hardest hit cities in Britain. ${ }^{7}$ Records also show Dundee gave a huge percentage of its young men to the forces during the war. When the Armistice finally came in 1918 there were 20,990 Dundee men on active service. With the addition of the killed and discharged wounded, the total was conservatively estimated at 30,490 at the end of the war - or $63 \%$ of eligible men in the city. ${ }^{8}$ This, too, represented a remarkable commitment to Britain's war-effort by the city's citizens. One specific example was the local 
territorial battalion of the 4th Black Watch, 'Dundee's Own', which was notable for representing all aspects of the city. The battalion arrived in France approximately 1000 strong at the end of February 1915 and fought at Neuve Chapelle and Aubers Ridge. ${ }^{9}$ However it was to be Loos that the battalion would forever be associated with, as it lost over half its strength killed or wounded (19 of the 20 officers, and 230 of the 420 rank and file), the majority in the first few hours of the battle. These grim statistics were repeated across cities, towns and villages all over Scotland but they tell only part of the story. One of the main objectives of the GWD project was a desire to rediscover the forgotten stories of life on the home front - how people and industries were affected by the war, and how those effects shaped the future of the city for generations to come. To achieve this, the project team needed to actively engage with the community and provide opportunities for everyone in the city and beyond to play a part in the centennial. In the longer term these activities would ensure that the unique stories of Dundee during the Great War were not only told in the most effective way but would remain accessible for future generations.

How audiences consume content digitally is constantly evolving. There is a growing expectation amongst digital-natives that content is available on demand, on multiple platforms and without cost. One of the challenges for any project where public engagement is crucial is to consider how the project's digital reach can be improved whilst minimizing the costs. From the outset the GWD partnership had an overarching aim to encourage research and foster learning. The project engaged with local schools, and has undertaken various public engagement events with a view to building better links between the city's heritage organizations, universities, press, local community and with wider external organizations such as the Imperial War Museum. This coordinated response to commemoration has allowed the city to make more effective use of existing resources. One of those resources is the rich digital heritage and buoyant community of digital artists, game developers and technologists. It was these connections that led to the desire to create a digital game that would engage, invoke and inspire new audiences to participate with the project. One of the core aspects to the game was the need to respectfully commemorate the 
sacrifices that many families had made during the conflict.

\section{Games, Commemoration and Remembrance}

Each year, at $11 \mathrm{am}$ on 11 November, the United Kingdom falls silent to commemorate the country's war dead. These acts of remembrance, together with the ceremonies and symbols that accompany them, have become an integral part of national life. They have a clear physical manifestation with the nation stopping to reflect for two-minutes often at monuments that were erected across the country in the 1920s. These monuments are focal points of the collective conscience but as new generations, more familiar with the digital world than the stone memorials in churches and town squares, emerge there is a growing need to consider and address the act of commemoration in a medium with which they are more familiar. Using games and digital technologies to attract and engage new audiences is not new or revolutionary, nor is using games to invoke empathy for specific topics amongst players. However, using a game as a commemorative project was recognized as being both different and challenging. If it wasn't for Dundee's digital heritage and the local networks that already existed across the city's cultural institutions, then it is entirely possible the idea for a game and other digital content would not have passed the initial talks. Despite the medium's increasing maturity there are still concerns over using a fundamentally interactive and playful medium to deal with significantly emotional topics. Games have too often failed at providing mature responses to challenging topics. As Game Journalist, Rob Fahey, has argued although games intersect "with many different fields of human experience" they are "still developing a language of interaction" and too often they struggle when attempting to deal with real themes.

There are topics our medium doesn't seem to be able to touch without causing harm...Race. Gender. Sexuality. Suffering. Love. Even violence, the lingua franca of so many games, is addressed with little delicacy. ${ }^{10}$ 
Previous scholarly work has established that games, and particularly military history games, can be considered as a form of interactive documentary. ${ }^{11}$ Certainly war and conflict continue to provide multiple narratives for what has been labelled the military-entertainment complex. ${ }^{12}$ While other mediums (literature, film and television) have engaged the broad spectrum of views from the overtly jingoistic and patriotic to the brutally anti-war, ${ }^{13}$ Games have generally eschewed complex narratives. Indeed, games have trended towards either simplistic 'good versus evil' tropes or to overtly complex simulations that avoid individual or personalised stories. One of the problems with the majority of historical games is that the fun is often to be had in playing and morphing the historical narrative. The interactive nature encourages players to play with the metes and bounds of the systems and therefore the story. That form of gameplay can often require designers to potentially ignore historical fact in favour of allowing player choice and freedom. The result is that despite the overwhelming popularity of games with historical settings and narratives, they have often been regarded as having little value as educational tools. ${ }^{14}$ However, over the past decade the technical barriers to game design and creation have been considerably lowered. Combined with the increasing digitisation of research and archive material, games are not just an increasingly important tool for visualizing data and disseminating research but are arguably a vital educational tool in allowing people to play with different and challenging historical narratives. Over the past few years we have seen an increasing interest in games that go beyond entertainment, games that utilise the medium to deliver differing views, messages and challenge player's preconceptions. Increasingly it has been shown that games can both entertain and deliver powerful commentary on the human condition and society.

Interactive media and games which explore challenging themes or aim to provide players with multifaceted and powerful emotional experiences have become increasingly common because of maturing audiences, availability of professional game development tools and a burgeoning independent (indie) game-making scene. The result has been a rise in the somewhat 
ill-defined "empathy game". These games aim to invoke empathy in the player and illicit emotional responses. Although empathy games range across all genres and technologies many use mechanics that disempower the player, rather than focusing rewarding and empowering, and this in turn has led to more interesting experiences. Brenda Braithwaite examined this in her Mechanic is the Message series and specifically with her historical board-game Train,${ }^{15}$ the premise of which is tasking players to load a train with passengers and transport the train to its destination. Only at the end do players discover that the destination of the train is Auschwitz, and are therefore presented with having to consider their own complicity based upon their actions in the game. Train is a strong argument for demonstrating that games can deliver an experience that goes beyond entertainment. However there still are some areas that developers have avoided. There are few games that deal with commemoration, remembrance and empathy for combat veterans, yet this is an area that is part of both our historical and collective consciousness.

One of the most powerful aspects of historical games is that they provide players the opportunity to visualize, interact and virtually experience events long past. However, most games rely on some form of replay value. Those where the focus is on an experience, as opposed to purely entertainment, can therefore be hindered in a commercial sense. After you know the outcome of Train the shock value is lost. Despite games with a war setting being one of the most popular genres, the mechanics are often shallow with little more than shooting and tactical simulations. In part this is one of the ongoing challenges that the medium has for cultural acceptance. Even where games have included some form of commemorative aspect the power and value of it is often diminished by the traditional reward mechanisms and the ability to respawn (player characters reappear after being killed). For example, EA's Battlefield series allows players to keep a permanent record of enemies that they have eliminated in multiplayer games by collecting of their dog tags. ${ }^{16}$ This acts as a reward mechanic for the victorious player but contravenes international law (other games depict the use of torture or the targeting of medical personnel) and has led the International Red Cross to voice their concerns. ${ }^{17}$ The Red 
Cross's alarm is that by permitting players to undertake illegal acts in games, however virtual, trivialises the real-world violations of the law of armed conflict and gradually such are perceived as acceptable behaviour. Games across the full spectrum of the industry have come in for criticism and this in turn impacts upon developers that are willing to explore more nuanced experiences.

\section{Military Games as Interactive Documentary}

There are a wide range of military-themed games, across multiple genres, that all have differing relationships with historical fact. Few are historically accurate though many claim authenticity. To the chagrin of historians many play fast and loose with the past, yet for players the game setting and historical accuracy are far removed from their primary concern of being entertained. Games and franchises, such as Battlefield, ${ }^{18}$ Call of Duty, ${ }^{19}$ and Medal of Honor, ${ }^{20}$ have commemorative aspects or could in some way be construed as interactive memorials, though few games have managed to create experiences that encourage players to reflect upon their actions. The challenge remains to create an historical game where loss matters without detracting from the player experience. The juxtaposition between respect for the player experience and the subject matter in most historical games has long created controversy.

An early game that attempted to convey loss and remembrance was Sensible Software's Cannon Fodder released in $1993 .{ }^{21}$ Cannon Fodder was a military-based action strategy shoot 'em up, and reflected the development studios irreverent humour. Given the considerable debate about violence in video games in the early 1990s, the game immediately found itself engulfed in controversy. The initial issue stemmed from the name and the use of a poppy as the box art which resulted in criticism from the Royal British Legion. The use of the poppy to promote a militarythemed game was controversial but was combined with the game tagline "War has never been so much fun" 22 and the unfortunate timing for the public unveiling of the game at a computer show at London's Olympia starting on Remembrance Sunday. Unlike other games of the period the 
initial controversy arose not from the gameplay but from the marketing campaign and this detracted from what has subsequently been described as a "profoundly moral game". ${ }^{23}$ Today it is difficult to fully appreciate the moral panic that games created in the early 1990s. Cannon Fodder's pixelated-cartoony graphical style and arcade action largely hid a game that "managed to be explicitly anti-war while still showing a respect for the men who fought and died through the years." 24 The core gameplay revolves around the player directing their troops through various missions, battling enemies, vehicles and installations along the way. Communication of the games underlying anti-war message was largely two-fold. The first was despite the game's title the player was not given an endless supply of nameless soldiers to use. When you lost a soldier or soldiers on a mission the game scrolled their names under a 'Lost in Service' banner book-ended on either side by a poppy. Secondly on the inter-mission screen, gravestones for each soldier lost were added to a hill as a queue of new recruits formed and replacements for those lost were welcomed by the recruiting officer. ${ }^{25}$ As Kieron Gillen stated, "By the end of the game, that grassy mound was a genuine cemetery. Look what you made." ${ }^{26}$ Cannon Fodder spawned two sequels and although some of the core ideas have been oft-repeated the uptake of the overall idea of an entertaining but essentially anti-war game has been incredibly limited. Considering that the games industry thrives on sequels, franchises and clones it is worth considering other titles, both large and small.

The Triple-A games market has increasingly used wars and conflicts for the setting of first-person shooters but the genre is generally regarded as glorifying war (the names alone are very jingoistic and patriotic e.g. Battlefield, Call of Duty, Medal of Honor, Brothers in Arms). There are aspects in many of these games that invoke some sense of loss and rudimentary forms of commemoration. Often this is in the form of connecting with the characters and narrative or building a squad and replaying missions so as not to lose a soldier. Some games continue the Cannon Fodder tradition with in-game memorials to those that you have lost, most recently Battlefield 1 has invoked a similar mechanic to convey the numbers lost in the First World War. ${ }^{27}$ 
Arguably the games narratives are deeper than they first appear, yet largely due to the basic mechanics, increased graphical realism and a penchant for controversy the games are often overlooked as cultural critiques of war. That said it is worth highlighting some games that do stand out for their historical and moral perspectives.

Brothers in Arms is centred around the player commanding a squad of paratroopers in the Second World War, initially in Normandy. The gameplay is based around authentic military tactics - the Four F's (find, fix, flank and finish). The player is encouraged to focus on taking cover, using one squad to suppress an enemy squad, and using another to flank and eliminate the enemy. ${ }^{28}$ The game mechanics thereby encourage players to problem-solve game situations by looking for them to move squads effectively to neutralise targets. The core mechanics were further enhanced by a strong narrative. Compared to other franchises and titles Brothers in Arms gradually introduced the player to a well-formed cast of characters, and then throughout the game put the loss of core characters as central to the narrative. Each success or achievement was made to feel hollow, and every advance undertaken with the knowledge that someone the player connected with is going to die. Overall the franchise is less visceral, and relates a more personal tale of a squad of soldiers desperately trying to survive the brutality of war.

The complications of dealing with more factual content was further demonstrated by the proposed game Six Days in Fallujah, which aimed to provide a realistic account of the Battle of Fallujah in the Iraq War. ${ }^{29}$ On creating a realistic military shooter, Atomic Games president Peter Tamte said "...a lot of that has to do with presenting players with the dilemmas that the Marines saw in Fallujah and then giving them the choice of how to handle that dilemma" ${ }^{30}$ Despite this lofty aim to create a moral understanding in players, Six Days in Fallujah was cancelled by its publisher Konami in response to public criticisms that the game was insensitive to the soldiers involved in the Iraq War. ${ }^{31}$ The result is that many military games actually shy away from trying to depict relatable instances of real-life military conflict. In some cases, such as Spec Ops: The Line, the attempt to tackle the brutality of war and how the human psyche adapts to the horrors 
that it faces during conflict are deliberately moved to a fictional setting. ${ }^{32}$ In others like Medal of Honor, Special Forces consultants requested that the developers focused on making the game 'authentic and plausible' rather than 'accurate and realistic'. ${ }^{33}$ The crux of this is that regardless of careful design, the market dictates and as long as interaction is owned by the player there remains scope for controversy.

\begin{abstract}
When historical events are seen through the eyes of video games, history itself becomes contingent — not only open to scholarly debate and interpretation, but open to each individual player's whim. ${ }^{34}$
\end{abstract}

The implication is that once a viewer of a media format has an inherent form of control over the actions of the characters involved, there then comes an important question of ethics: To what degree, if any, should a player be able to re-enact historical events in the past and if so, then how much access should they have to the scenarios that have previously caused turmoil for those involved?

Smaller games, often developed by independent developers and self-published provide a different experience of conflict. While undoubtedly lacking the graphical realism of big-budget games, relatively simple game mechanics can be used effectively. For example, Gonzalo Frasca's September 12th explores the War on Terror ${ }^{35}$ and both Molleindustria's Unmanned and Biome Collective's Killbox critique drone warfare. ${ }^{36}$ More complex games such as This War of Mine place the player in a war-torn city not as an elite soldier but as a group of civilians trying to survive in a besieged city. ${ }^{37}$ It is often these independent studios that have been more willing to turn their attention to the First World War (or in the case of Ubisoft's Valiant Hearts: The Great War a smaller team in a large company). ${ }^{38}$ Games such as the first-person shooter Verdun,${ }^{39}$ the flight simulator Rise of Flight,${ }^{40}$ or the strategy game Victoria $I I,{ }^{41}$ all tend to be relatively unique for their genre in focusing on the First World War. As David Hussey has stated 
one of the possible reasons that the First World War is relatively under represented is that unlike the Second World War there is "no obvious villain". ${ }^{42}$ Another aspect is that the war has been under represented in other media. The challenge for many of the commemorative projects is not just that the war is now outside of living memory (in that no one who participated in the war remains) but also that few people really understand the causes of the war and that makes the narrative harder to understand. Other aspects that limit its adoption are that the sense of futile loss is compounded because of the Second World War. In many of the War Memorials the names of those lost against the Axis powers in the clearer "good versus evil" narrative of the Second World War are dwarfed by those lost in the First. While the latter conflict still deeply affected communities, the fact remains that the First World War's initial recruitment drives actively encouraged fathers, sons, brothers and colleagues to join up together and fight together in Territorial or Volunteer (the so-called "Pals") battalions. The impact of this policy often left entire communities decimated after large-scale battles such as Loos or the Somme. ${ }^{43}$ Arguably another factor that should be considered is that the First World War still holds a place in the collective consciousness of many nations because the perceived futility of the conflict endures respect. Whilst other wars provide a clear narrative or even the need for further discussion, the first great conflict of the twentieth century still has an impact on the collective memory. It is after all the war that was brought to an end at 11 am on the 11 November, a time and date that focuses commemoration each year. The centennial of the war was recognized nationally in the United Kingdom as an opportunity for greater understanding of the conflict. The HLF dedicated specific funds for projects to look at not just the events of the war but its impact upon society. The broad goals of the HLF included considering the experiences not just of those that served in the armed forces, but in examining the role of women, together with the places affected by the war, and how the war has since been commemorated and interpreted. The GWD project was therefore set up to help uncover the stories and explore what the conflict means today for the City of Dundee, and the initial plan anticipated creating a small empathy game that embraced the core HLF themes. 


\section{Digital Commemoration and Great War Dundee}

The tentatively titled In Flanders Fields, was to be a first-person, empathy game that explored the stories of Dundee soldiers who never returned from the Great War. The game design and development would draw on the city's knowledge and expertise in the gaming industry, combined with the expertise of the Great War Dundee partner organizations. ${ }^{44}$ The game would use local archives of letters and historical references to the period, and relate this to the real people involved. The gameplay consisted largely of player exploration and uncovering hidden objects and then provided additional narrative about that person and their role in the war. Overall the game would use the medium to explore the memories they left behind, humanizing the victims, paying homage to their lives, and those of their friends and families. The audience for the game was to be broad covering those with an interest in the First World War including Schools, Museums and an age range of five or older. Although the focus was to be on Dundee for the main story, the game was also intended to work for and be applicable to communities throughout the United Kingdom. The core features were to foster learning through the use of the personal stories, but also to allow these story elements to be editable, encouraging other projects or communities to use the game and to reflect stories that were discovered through the centennial projects. Aesthetically the game was to have an abstract style. Simplistic or monochromatic color schemes were to be favored with few textures. This was designed to help frame the setting. Where the player navigated fields that had been scarred, but had somewhat recovered from the effects of the War. There was to be a sense of redemption and healing to the visuals and the presentation. The audial style was to be relaxing but also realistic. The sound effects were aimed at allowing the player to close their eyes and imagine they are standing in that field. The focus on the war was explored through an implied narrative set along a guided, but optionally exploratory path. The narrative was therefore to be important to the mechanics, and conversely, the mechanics essential to the narrative. The game, in a word, was ambitious and although the game was not to move beyond the design phase, the process proved vital in the 
development of other content.

There are several reasons that the design direction of the digital commemoration changed. From nuances in the funding application as to what constituted creative work, through the availability of the core team, to the ownership and intellectual property of archive material and its digitization and application in a game. There were also concerns about whether the game was the right vehicle to foster engagement but also remain respectful to the commemoration aspects of the project. Though the design intended to avoid potential controversy there were often practical considerations that shaped decisions. For example, with an abstract style the player would have to create the world partly in their imagination. The design therefore allowed avoidance of more visceral elements and that helped too in exploring difficult subjects. On a practical level realistic graphics were simply beyond the budget. It is more difficult to do realism justice, and one of the potential issues with a realistic game is that even something as simple as a low-resolution texture could be taken out of context as not treating the subject with due reverence. Similarly, the focus of the core interactions with objects (or keepsakes) maintained a sense of decency and allowed the player to explore the topic in a more personal way as opposed to focusing on a combat mechanic. There was a practical element to the design as it meant that the framework could be used for multiple objects and narratives. Another issue was the intention to use real stories and people. This aspect where the history is interpreted and then abstracted through the game created a problem in that it required the disclosure of real names to be authentic. However, the personal and private nature of letters with real names could potentially uncover or compromise information about living relatives or descendants. Interpreting narratives based on archive material is common historical practice, doing it through a game though risked being perceived as doing it for entertainment. Thus, the larger issue of what a game actually is and the perception of history as entertainment created a problem that was difficult to maneuver through. Often the wider public doesn't hear as much about the positive aspects of games through the mainstream press. Games are more known for their violence or sexism and are not 
as widely known for their documenting properties, or their deeply explorative ability. The issue with names is a good example of where history and the medium could conflict. In considering their use, the easiest solution was to remove real people's names, but that endangered the historical accuracy. Similarly, fictionalizing the names or amalgamating the stories of many into few though preferable was less than ideal. An alternative option was to use only stories that the project had full permission for (or where that permission could be obtained) but that inevitably risked the best narratives being removed.

As the project and development team wrestled with these design decisions the overall project evolved. As part of the dissemination requirement there was a need for a website and the original intention to use existing web content was hindered due to the existence of multiple archival records being behind paywalls. The aims of GWD and the HLF to make content freely available could therefore not be fully achieved and necessitated a change in direction. The decision was made to incorporate some of the game elements into a wider digital strategy for the overall benefit of the project and public. The result was the creation of web, video and interactive content that utilized various storytelling and gaming techniques to bring the story of the First World War home to Dundee. This solution would not only treat the stories and history respectfully, but would be educational, interesting and crucially a growing resource for the public. Finally, this approach provided a wider digital memorial to those that lost their lives in battle and equally to those that survived the conflict only to live with the memories for the rest of their lives.

One of the core reasons for moving towards a wider digital approach as opposed to a game was to provide a digital home for Dundee's Roll of Honour and to invite the public to enhance individual records with additional personal information and picture content. ${ }^{45}$ This was something that simply wasn't possible to incorporate into a game. Given the aim of fostering engagement it became important to present the broad story of the war to enable all users to appreciate and understand Europe in 1914 and how the war started and escalated so quickly. It was felt this would provide a background and context to connect with the people of that period, 
as well as a sense of what Dundee was like at the time. The wider digital approach focused on people, place and time. The stories originally envisioned to be told through the game became less abstract and more detailed. Rather than focus on any real individual the decision was made to fictionalize six characters and allow these composite character's (of different real people) lives to help map people's own journey's through the archive and historical research. ${ }^{46}$ The objective was to combine the background story of the war with the Roll of Honour to provide the means to place individuals in the wider timeline and become part of the larger story. The challenge of attaining public engagement in the project and in uploading personal content was mitigated by digitizing the existing paper-based Roll of Honour and through the release of further digital content in the form of an interactive documentary to reach a wider audience.

The decision was made to create an interactive documentary that Dundonians would empathize with telling the story of the city. This was to focus on the impact that the Battle of Loos had upon the City of Dundee. Loos has been described as an unwanted battle and certainly it achieved little of its aims. ${ }^{47}$ For Scotland, it had significant ramifications with every Scottish regiment represented by thirty-six battalions (approximately half the number which participated in the opening stages of the battle) so that no area of Scotland was spared a share of the casualties. The large number of Scots, who went over the top at 6.30 a.m. on 25 September 1915, ensured Loos would be remembered as a Scottish battle. ${ }^{48}$ While Loos had ramifications for almost every community in Scotland, Dundee's experience of the Great War became synonymous with the fate of its Territorial Force battalion, 4th Black Watch, and to this day the war memorial is lit on the 25 September each year. It was the impact that Loos had on the $4^{\text {th }}$ and Dundee, together with a local perception that there wasn't a street or tenement that wasn't affected, that led to the development of the visualization component in Loos: The Fallen Fourth.${ }^{49}$ The interactive documentary was developed around the 1915 city map of Dundee and told the city's story of the battle. The core aspect of the design was to bring 'viewers' closer to the human cost, by focusing on a single battalion, in just one battle of the war and to contrast this with the impact that those casualties had upon the city. The 20-minute visualization used 
various game and narrative techniques to provide viewers with a fresh and dramatic perspective of the war. The interactive documentary begins by placing various groups (war resistors, women, military and voluntary organizations) in the context of the city (see Figure 1) and battle location to bring the subject closer to the viewer (See Figure 2) It then starts building up tension through the presentation of the deaths suffered by the 4th Black Watch in the first two days of the Battle of Loos (see Figure 3). The aim was to provide visually striking moments for viewers to consider the impact upon the communities left behind. The linear narration was enhanced by allowing viewers to pause to explore and interact with the map and delve deeper into the wider stories uncovered by the GWD project team. The interactive documentary and the website were successfully launched at the national commemoration for the anniversary of Loos on the 25th September 2015. Engagement and feedback received indicated that the broader strategy succeeded in engaging with a wider audience. The project has also proven that providing the opportunity to digitally preserve privately owned material which might otherwise have been lost, is an aspect that the public will engage with and is already uncovering fresh research perspectives. ${ }^{50}$ Further information on individual participants in the war and family members are being collated and updated regularly

\section{Conclusion}

The digital projects have helped raise awareness of Dundee's significance during the Great War and to tell the stories that humanize that history, helping people make personal connections to their past. Through the website and interactive documentary analytics the GWD project could reach the wider Dundee diaspora. The project completed an education pack for use in schools and looks to move forward with further projects and events to reflect the ongoing and future commemoration events. ${ }^{51}$ The opportunity to make a game may not have been fully realized but the initial ambition and game design exercise were fundamental in shaping the creation of the wider digital legacy.

One of the challenges for projects that focus on history is in engaging with the wider 
public and younger generations. In an increasingly interactive world, audiences expect to be able to engage with a wide range of digital content. Within that games and interactive documentary have a significant role to play as apparatuses for exploring complex subjects and issues. As the creative toolsets and means of producing games and digital content are increasingly lowered there should be an increasing use and acceptance of games and digital content as means of disseminating research to wider audiences. However careful concern still needs to be given to the use of games when considering wider historical themes and their correlation to society. The HLF-funded project, Great War Dundee, demonstrates the complexity of designing with historical accuracy in mind but also the impact that game design can have in planning and disseminating research. The exercise undertaken in understanding previous games attempts at dealing with loss, commemoration and remembrance together with designing for the medium of games directly shaped the wider project dissemination. The result has been an exploration of wide ranging narratives that reflect the diversity of an industrial city prior to the First World War. The use of games design and technology to challenge the myths that develop over a century of remembrance but also to effectively visualize social, economic and cultural structures of the city Dundee has led to not only better public engagement but is shaping further research on the conflict from the perspectives of the local community. The design exercise of In Flanders Fields and its influence on the creation of Loos: The Fallen Fourth demonstrates that games can be utilized to provide a different perspective. Furthermore, encouraging the dissemination of historical research to wider audiences through games and digital content can help foster community engagement in history from a local community perspective.

\section{Acknowledgements}

The research presented here was funded by the Nine Trades of Dundee through their internship program and was part of the Heritage Lottery Funded Great War Dundee project. The author gratefully acknowledges the financial support and would like to thank all the partners of the Great War Dundee project. 
Images

\section{COPYRIGHT IS AUTHORS.}

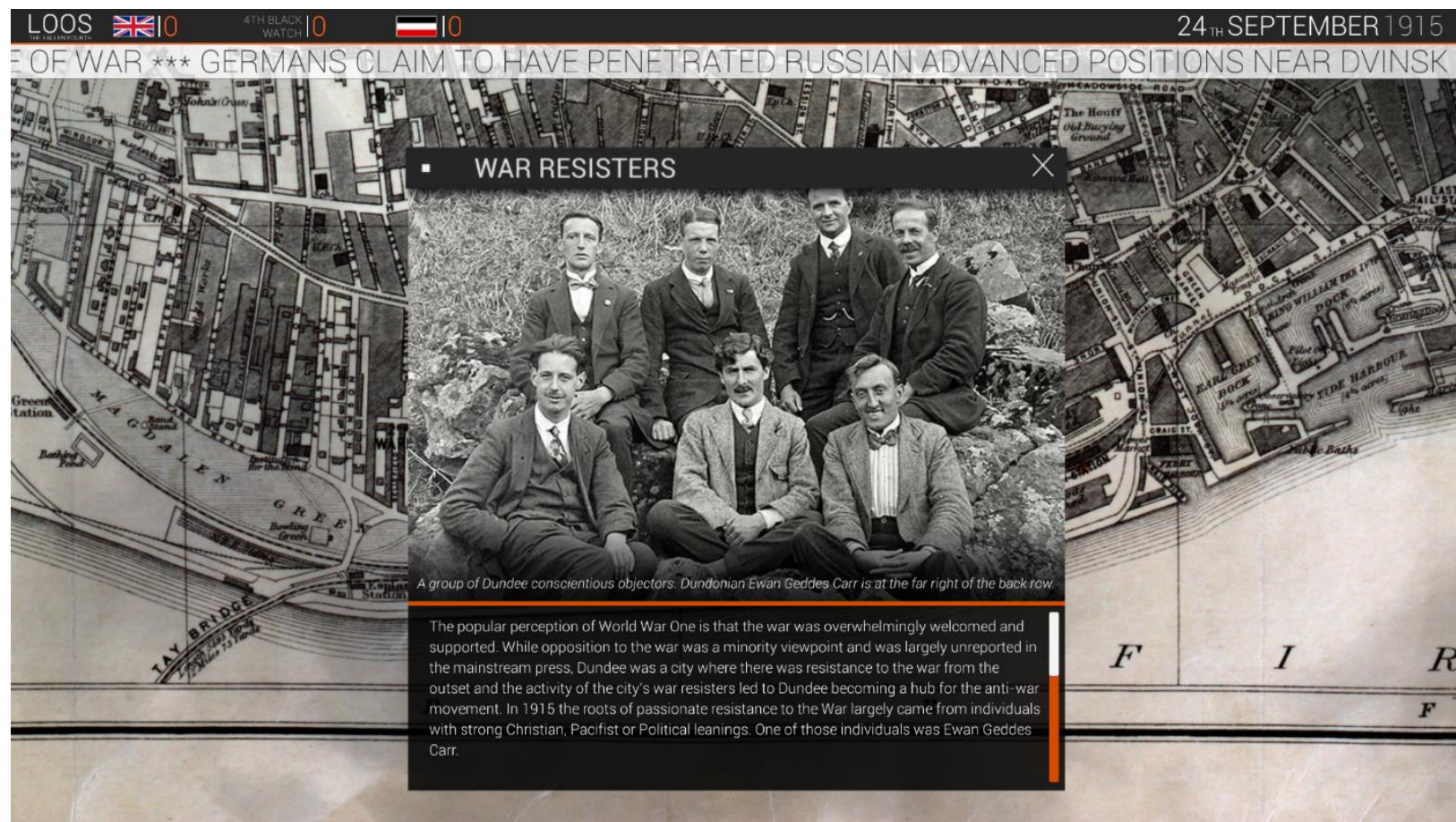

Figure 1: Loos: The Fallen Fourth 'A City at War' - showing the panel describing the war resistance and conscientious objectors' movement in Dundee.

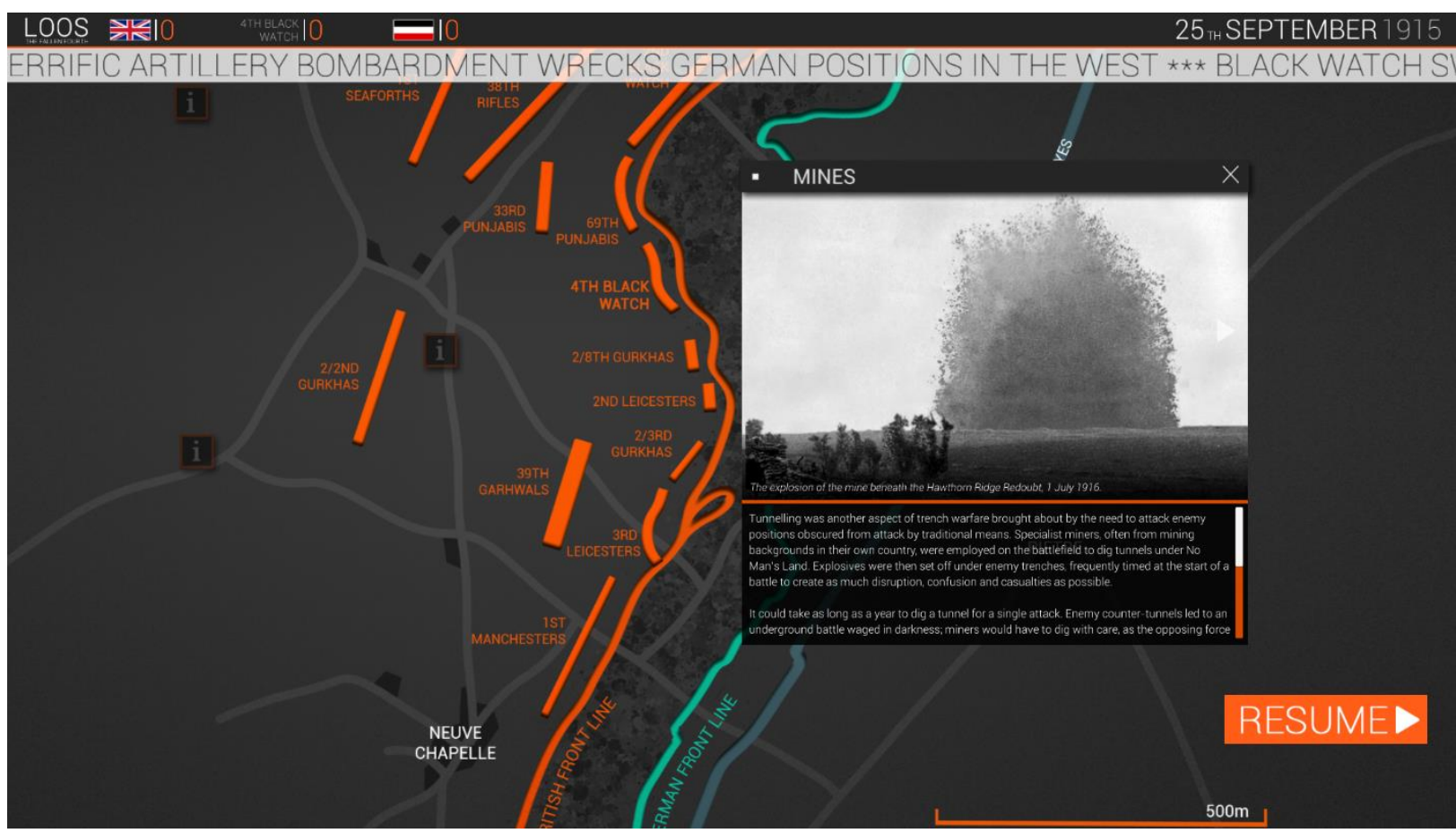

Figure 2: Loos: The Fallen Fourth 'The Front' - showing the panel describing the use of mines in the battle and interactive map of the order of battle. 


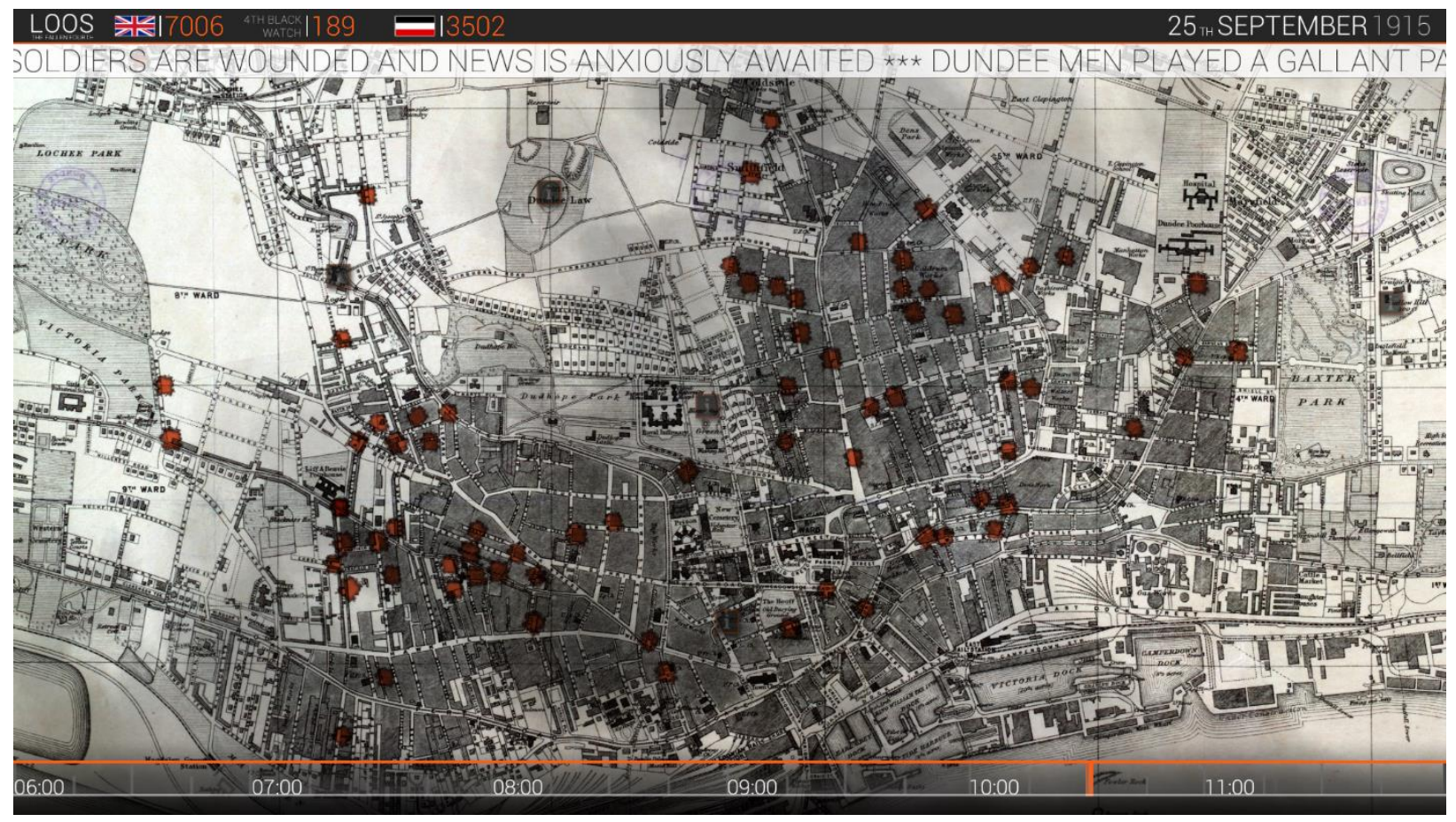

Figure 3: Loos: The Fallen Fourth 'Impact of Loos' - showing the timeline of the casualties of Loos upon their home addresses in Dundee. 
${ }^{1}$ Analyst firm Newzoo estimates that there are currently 2.2 billion gamers worldwide. McDonald, Emma. 2017. "The Global Games Market 2017". Newzoo. https://newzoo.com/insights/articles/the-global-games-market-willreach-108-9-billion-in-2017-with-mobile-taking-42/.

2 The lexicon "the medium is the message" was defined in McLuhan's 1964 text Understanding Media but has been influential and updated by games academics such as Brenda Braithwaite and Jane McGonigal. McLuhan, Marshall. 2013. Understanding Media. Cambridge (Mass.): The MIT Press; Brenda Braithwaite, "Gaming For Understanding" filmed 2011, TED video, 9:17.

http://www.ted.com/talks/brenda_brathwaite_gaming_for_understanding;

McGonigal, Jane. 2011. Reality Is Broken: Why Games Make Us Better and How They Can Change The World. New York: Penguin Press.

${ }^{3}$ Jenkins, Henry, and Mark Deuze. "Convergence Culture." (2008): 5-12; Bogost, Ian. "Comparative Video Game Criticism." Games and Culture 1, no. 1 (2006): 41-46; Mäyrä, Frans. An Introduction to Game Studies. Sage, 2008. Stenros, Jaakko, Markus Montola, and Frans Mäyrä. "Pervasive Games in Ludic Society." in Proceedings of the 2007 conference on Future Play, pp. 30-37. ACM, 2007.

${ }^{4}$ Prensky, Marc. "Digital Natives, Digital Immigrants Part 1." On the Horizon, vol. 9, no. 5 (2001): 1-6.

${ }^{5}$ Great War Dundee. "About." greatwardundee.com. https://www.greatwardundee.com/about/ (accessed February 8, 2018).

${ }^{6}$ Sleight, Christopher. 2009. "BBC News - How Dundee became a world gaming hub". BBC Tayside and Central, 2009. http://news.bbc.co.uk/1/hi/scotland/tayside_and_central/8399935.stm.

${ }^{7}$ Lindsay, Caroline. "First World War: share your family's stories" The Courier, February 17, 2014.

http://www.thecourier.co.uk/news/history-2.1462/first-world-war-share-your-family-s-stories-1.227114. (accessed February 8, 2018.)

8 “Dundee's Glorious Dead," The People's Journal, May 16, 1925.

${ }^{9}$ Wauchope, Arthur Grenfell. 1925. A History of the Black Watch [Royal Highlanders] in the Great War, 19141918. Vol. II, London: Medici Society.

${ }^{10}$ Fahey, Rob. 2012. "A Question of Maturity". Gamesindustry.biz. http://www.gamesindustry.biz/articles/2012-0706-a-question-of-maturity.

${ }^{11}$ Fullerton, Tracy. "Documentary games: Putting the player in the path of history." Playing the past: Nostalgia in video games and electronic literature (2008): 215-238; Galloway, Dayna, Kenneth B McAlpine, and Paul Harris. 2007. "From Michael Moore To JFK Reloaded: Towards a Working Model of Interactive Documentary". Journal of Media Practice, 8 (3): 325-339. doi:10.1386/jmpr.8.3.325_1.

${ }^{12}$ Herz, Jessie Cameron. 1997. Joystick Nation: How Videogames Ate Our Quarters, Won Our Hearts, And Rewired Our Minds. Boston, Mass. [u.a.]: Little, Brown, and Co; Lenoir, Timothy. 2000. "All But War is Simulation: The Military-Entertainment Complex". Configurations 8 (3): 289-335. doi:10.1353/con.2000.0022; Andersen, Robin, and Marin Kurti. 2009. "From America's Army To Call Of Duty: Doing Battle With The Military Entertainment Complex". Democratic Communiqué, 23 (1). http://journals.fcla.edu/demcom/article/view/76373.

Robinson, Nick. 2012. "Videogames, Persuasion And The War On Terror: Escaping Or Embedding The MilitaryEntertainment Complex?". Political Studies 60 (3): 504-522. doi:10.1111/j.1467-9248.2011.00923.x.

${ }^{13}$ Landy, Marcia. 2001. The Historical Film: History and Memory in the Media. London: Continuum International Publishing Group.

${ }^{14}$ Kapell, Matthew, and Andrew B. R. Elliott. 2013. Playing With The Past: Digital Games And The Simulation Of History. New York: Bloomsbury Academic.

${ }^{15}$ Braithwaite, Brenda, and John Sharp. "The mechanic is the message: A post mortem in progress." Ethics and game design: Teaching values through play (2010): 311-329.

${ }^{16}$ Battlefield series, developed by EA DICE. (2002; Redwood City, California: EA).

17 See International Committee of the Red Cross. 2013. "Video Games And Law Of War". icrc.org.

https://www.icrc.org/eng/resources/documents/film/2013/09-28-ihl-video-games.htm and International Committee of the Red Cross. "Video Games get Real". Filmed [2013]. YouTube video, 3:11 Posted [September 2013].

https://www.youtube.com/watch?v=7SIIJNgeuRc.

${ }^{18}$ Battlefield 4, developed by EA DICE. (2013; Redwood City, California: EA) Xbox 360.

${ }^{19}$ Call of Duty: Modern Warfare, developed by Infinity Ward. (2007; Santa Monica, California: Activision) Xbox 360; Call of Duty: Modern Warfare 2, Developed by Infinity Ward. (2009; Santa Monica, California: Activision) Xbox 360; Call of Duty: Black Ops, developed by Treyarch. (2010; Santa Monica, California: Activision) Xbox 360; Call of Duty: Black Ops II, developed by Treyarch. (2012; Santa Monica, California: Activision) Xbox 360.

${ }^{20}$ Medal of Honor, developed by Danger Close Games. (2010; Redwood City, California: EA) Xbox 360.

${ }^{21}$ Cannon Fodder, developed by Sensible Software. (1993; London: Virgin Interactive Entertainment), PC.

${ }^{22}$ Mott, Tony. 2013. 1001: Video Games You Must Play Before You Die. United Kingdom: Cassell Illustrated.

${ }^{23}$ Gillen, Kieron. 2007. "Retrospective: Cannon Fodder".

http://www.rockpapershotgun.com/2007/11/11/retrospective-cannon-fodder/.

${ }^{24}$ Gillen, Kieron. 2007. "Retrospective: Cannon Fodder".

http://www.rockpapershotgun.com/2007/11/11/retrospective-cannon-fodder/. 
${ }^{25}$ Snape, Joel. 2013. "Never Been So Much Fun: The Making Of Cannon Fodder".

http://www.eurogamer.net/articles/2013-12-04-never-been-so-much-fun-the-making-of-cannon-fodder.

${ }^{26}$ Gillen, Kieron. 2007. "Retrospective: Cannon Fodder".

http://www.rockpapershotgun.com/2007/11/11/retrospective-cannon-fodder/.

${ }^{27}$ Battlefield 1, developed by EA DICE (2016; Redwood City, California: EA) PlayStation 4.

${ }^{28}$ Griffin, Ben, 2014. "Reinstall: Brothers in Arms". http://www.pcgamer.com/reinstall-brothers-in-arms/. See also Brothers in Arms: Road to Hill 30, developed by Gearbox Software, (2005; Montreuil, Paris: Ubisoft) Xbox;

Brothers in Arms: Earned in Blood, developed by Gearbox Software. (2005; Montreuil, Paris: Ubisoft) Xbox;

Brothers in Arms: Hell's Highway, developed by Gearbox Software, (2008; Montreuil, Paris: Ubisoft). Xbox 360.

${ }^{29}$ Suellentrop, Chris. 2010. "War Games". New York Times Magazine.

http://www.nytimes.com/2010/09/12/magazine/12military-t.html

${ }^{30}$ Nelson, Randy. 2009. "Joystiq Interview: Six Days in Fallujah". Engadget.

https://www.engadget.com/2009/04/13/joystiq-interview-six-days-in-fallujah/.

${ }^{31}$ Jenkins, David. 2014. "Konami Drops Controversial Six Days in Fallujah". http://www.gamasutra.com/php-

bin/news_index.php?story=23367.

32 Pitts, Russ. 2012. "Don't be a Hero - The Full Story Behind Spec Ops: The Line".

http://www.polygon.com/2012/11/14/3590430/dont-be-a-hero-the-full-story-behind-spec-ops-the-line. See also

Spec Ops: The Line, developed by Yager Development. (2012; Novato, California: 2K Games) Xbox 360.

${ }^{33}$ Suellentrop, Chris. 2010. "War Games". New York Times Magazine.

http://www.nytimes.com/2010/09/12/magazine/12military-t.html.

${ }^{34}$ Moore, M. R. 2010. "Adaptation and New Media". Adaptation 3 (2): 179-192. doi:10.1093/adaptation/apq010.

${ }^{35}$ September $12^{\text {th }}$, developed by Gonzalo Frasca, (2003; Newsgaming.org), PC.

${ }^{36}$ Unmanned, developed by Molleindustria. (2012; Molleindustria), PC; Killbox, developed by Biome Collective.

(2015; Dundee: Biome Collective), PC.

${ }^{37}$ This War of Mine, developed by 11-bit Studios. (2014; Planegg, Germany: Deep Silver). PC.

${ }^{38}$ Valiant Hearts: The Great War, developed by Ubisoft Montpellier. (2014; Montreuli-sous-Bois: Ubisoft), PC.

${ }^{39}$ Verdun, developed by BlackMill Games. (2013; BlackMill Games), PC.

${ }^{40}$ Rise of Flight: The First Great Air War, developed by 777 Studios. (2009; 777 Studios) PC.

${ }^{41}$ Victoria II, developed by Paradox Development Studio. (2010; Stockholm: Paradox Interactive), PC.

${ }^{42}$ Hussey, David R. 2014. "Commemoration, Video Games, And Remembrance Day". Playthepast.org. http://www.playthepast.org/?p=5026.

${ }^{43}$ McFarland, Elaine, Catriona M.M. MacDonald, and E. W. McFarl. 1999. Scotland and the Great War. East Lothian, Scotland: Tuckwell Press.

${ }^{44}$ Great War Dundee. "About - Partner Information" greatwardundee.com.

https://www.greatwardundee.com/about/partner-information (accessed February 8, 2018).

${ }^{45}$ Great War Dundee. "Roll of Honour" greatwardundee.com. https://www.greatwardundee.com/ roll-of-honour (accessed February 8, 2018).

${ }^{46}$ Great War Dundee. "Six Lives of WW1" greatwardundee.com. https://www.greatwardundee.com/\#fndtn-sixlives (accessed February 8, 2018).

${ }^{47}$ Warner, Philip. 1976. The Battle of Loos. Ware, Hertfordshire: Wordsworth Editions.

${ }^{48}$ Royle, Trevor. 2011. The Flowers of the Forest: Scotland and the First World War. Edinburgh: Birlinn.

${ }^{49}$ Great War Dundee. "Loos: The Fallen Fourth." greatwardundee.itch.io. https://greatwardundee.itch.io/loos-the-

fallen-fourth (accessed February 8, 2018).

${ }^{50}$ These include the story of a young deserter shot at dawn which led to the creation of a digital comic (available at: https://www.greatwardundee.com/the-home-front/shot-at-dawn) through to the networks of emigrants who returned to fight or those that developed to oppose the war.

${ }^{51}$ Great War Dundee. "Resources" greatwardundee.com. https://www.greatwardundee.com/resources (accessed

February 8, 2018). 